Case Report

\title{
SCROTAL CALCINOSIS - RARE CASE REPORTS OF TWO CASES
}

\author{
Harish S. Permi ${ }^{1}$, Rohan Shetty ${ }^{2}$, Shalmali Alva ${ }^{3}$, Balakrishna Shetty ${ }^{5}$, \\ Rajesh Ballal ${ }^{6} \&$ Jayaprakash Shetty $K^{4}$ \\ ${ }^{1}$ Associate Professor, ${ }^{3}$ Senior Resident, ${ }^{4}$ Professor \& Head, Department of Pathology \\ ${ }^{2}$ Assistant Professor, ${ }^{5}$ Professor, ${ }^{6}$ Professor \& Head, Department of Surgery \\ K.S. Hegde M edical Academy, Nitte University, M angalore - 575018 \\ Correspondence: \\ Harish S. Permi, \\ Mobile : 9964131827 Email: drharish01@gmail.com.
}

\begin{abstract}
:
Scrotal calcinosis is a benign disease characterized by multiple calcified scrotal nodules. The nodules develop slowly over many years and patients usually do not seek for treatment, until they grow to large size. Histopathological examination shows deposition of basophilic amorphous material surrounded by giant cell granulomatous reaction. We report two cases of scrotal calcinosis occurring in 27 year and 45 year old males who presented with multiple scrotal swellings. Clinical diagnosis was multiple sebaceous cysts. On histopathology, excised swellings showed deposition of calcium with giant cell reaction. On regular follow up both are doing fine without any recurrence.
\end{abstract}

Keywords: Scrotal calcinosis, sebaceous cysts, calcification.

\section{Introduction:}

Scrotal calcinosis $(\mathrm{SC})$ is a rare benign local process characterized by multiple, painless, hard scrotal nodules in the absence of any systemic metabolic disorder. ${ }^{(1)}$ Histologically, SC is characterized by the presence of calcium deposits that are variable in size within the dermis, often surrounded by a foreign body-type granulomatous reaction. (2) Numerous theories have been reported regarding the possible etiology of SC; the most popular ones including dystrophic calcification of pre-existing epithelial cysts and purely idiopathic origin. The presence of normal values of calcium and phosphorus along with this spectrum of changes in histology both support the theory that these form by dystrophic calcification of epithelial cysts in a progression that involves inflammation, rupture, calcification and obliteration of the cyst wall. ${ }^{(1)}$ We report two cases of scrotal calcinosis presented with multiple scrotal swellings. Clinical diagnosis was multiple sebaceous cysts, which were excised. Histopathological examination showed deposition of basophilic amorphous material (calcification) with giant cell reaction. On follow up both of them are fine without any recurrence.

\section{Case Report :}

Case 1) A 27 year old male presented with multiple scrotum swellings since one year. Local examination revealed multiple swellings on the scrotum, which were nontender, cystic and firm-hard in consistency, larger measured $2 \times 1$ cms. Routine haematological, biochemical and serological investigations were within normal limits. HIV and HBsAg were nonreactive. Excision of scrotal skin with the multiple swellings was done and sent for histopathological examination. Grossly the skin covered specimen measured $5.5 \times 3.5 \times 2.5 \mathrm{cms}$. Surface showed multiple swellings which were cystic, firm to hard in consistency. (Figure 1) Cut section revealed chalky white friable tissue. Microscopy showed skin beneath which deposition of basophilic material (calcification) surrounded by inflammatory reaction consisting of lymphocytes, plasma cells and multinucleated giant cells seen (Figure 2). Adjacent area showed cyst lined by stratified squamous epithelium. Final diagnosis of scrotal calcinosis was considered. On follow up he is doing fine.

Case 2) A 45 year old male presented with multiple scrotal swellings since 10 years. Local examination showed multiple scrotal nontender swellings which were cystic, firm to hard in consistency, larger measured $1.5 \times 1 \mathrm{cms}$. Routine haematological, biochemical and serological investigations were within normal limits. HIV and HBsAg 
were nonreactive. Excision of scrotal skin with multiple swellings was done and sent for histopathological examination. Grossly the skin covered specimen measured $4 \times 3 \times 2 \mathrm{cms}$. Surface showed multiple swellings which were cystic, firm to hard in consistency. Cut section and microscopy showed similar features as seen in case one, but without any fibrous capsule or epithelial cysts. On regular follow up he is fine.

\section{Discussion :}

Scrotal calcinosis consists of nodules within the dermis of the scrotal skin varying in size and number and develops slowly over many years. ${ }^{(3)}$ It occurs mainly in 20-40-yearold males, and usually onsets in childhood or adolescence. Multiple scrotal nodules could be observed in most patients, and the nodules are hard and yellowish or write, with various sizes from several $\mathrm{mm}$ to $\mathrm{cm} .{ }^{(2)}$ The condition is benign and although they are mostly asymptomatic, a feeling of heaviness in the scrotum, discharge and itching are the most frequently encountered complaints. ${ }^{(3)}$ Our cases presented with multiple painless scrotal swellings. Clinically scrotal calcinosis may be confused with

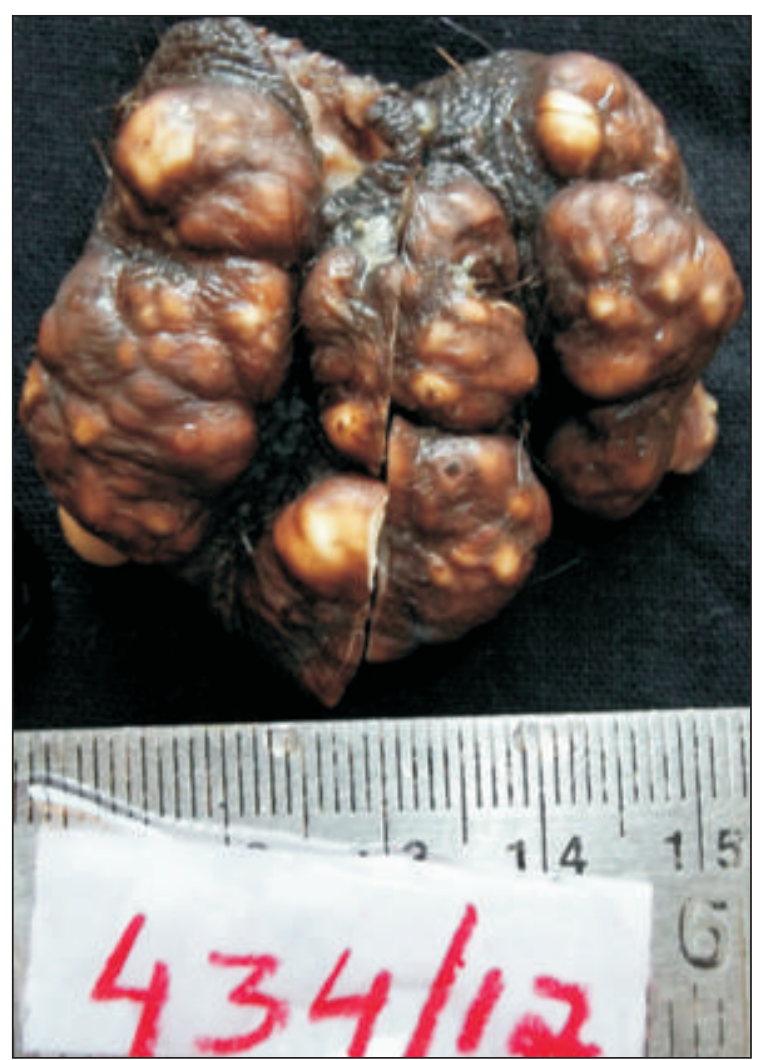

Figure 1: Gross showing scrotal skin with multiple swellings epidermal inclusion cyst, steatocystoma, cutaneous horn (actinic keratosis), and other benign tumors, such as lipoma, fibroma, angiokeratoma, and lymphangioma circumscriptum; a definitive diagnosis is based on histology. ${ }^{\left({ }^{1}\right)}$ The discussion of pathogenesis focuses on the role of epidermal cysts in SC. Epidermal cysts were calcified with partial or total disintegration of the epithelial walls, associated with an inflammatory reaction. ${ }^{(4)} \mathrm{A}$ pathogenic pattern based on histopathological finding, clarified that cysts (epidermal, pilar or hybrid) are formed, implying calcification of the intracystic keratinous content with enlargement of the cyst and a subsequent attenuation of the wall. This triggers a mononuclear cell inflammation or foreign body granuloma with resorption of the cyst walls and of the keratinous material. Finally only calcified deposits remain. It was considered that histopathological findings varied with the age of the cysts, the oldest lesions no longer containing epithelial cells. ${ }^{(5)}$ The nodules were found separated by fibrous connective tissue, and surrounding by infiltrated inflammatory cells and a foreign body-type granulomatous reaction, but without any identifiable epithelial structure or fibrous capsule. ${ }^{(2)}$ In one of our case, there was a cyst lined by stratified squamous epithelium adjacent to deposition of calcium surrounded by giant cell granulomatous reaction suggesting dystrophic calcification of pre-existing epithelial cyst. The other case showed only deposition of calcium with giant cell granulomatous reaction separated by fibrous connective tissue, without any fibrous capsule or epithelial structure

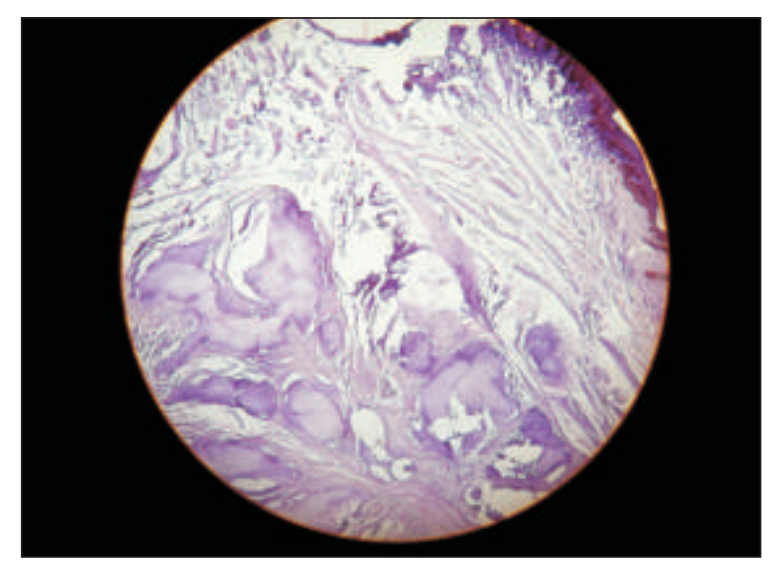

Figure 2: Microscopy showing skin beneath which deposition of basophilic material (calcification) surrounded by giant cell granulomatous inflammatory reaction. (Hematoxylin \& Eosin X 100) 
suggesting idiopathic nature of scrotal calcinosis. Surgical excision must be limited to the scrotal skin since calcified nodules are localized within the dermis. ${ }^{(6)}$ In both of our cases, surgical excision was limited to scrotal skin. On follow up both of them are doing fine without any recurrence.

\section{References:}

1. Suparna Dube, Rajeev Sharma, Veena M aheshwari. Scrotal calcinosis: Idiopathic or dystrophic? Dermatology Online Journal 2010; 16: 5.

2. Dan Li, Jiaowei Gu, Ziliang Tu, Qinghong Zhu, Che Zhang. Scrotal calcinosis: A case report. Int J Surg Case Rep 2010; 1: 22-23.

3. Alper Parlakgumus, Emine T Canpolat, Kenan Caliskan, Tamer Colakoglu, Sedat Yildirim, Ali Ezer Turgut Noyan. Scrotal calcinosis due to resorption of cyst walls: a case report. Journal of Medical Case Reports 2008; 2:375.

4. Swinehart J.M , Golitz L.E. Scrotal calcinosis: dystrophic calcifications of epidermoid cysts. Arch Dermatol 1982; 118:985-8.

5. Song D.H, Lee K.H, Kang W.H. Idiopathic calcinosis of the scrotum: histopathologic observations of fifty-one nodules. J Am Acad Dermatol 1988; 19:1095-1101.

6. Ruiz-Genao D.P, Rios-Buceta L, Herrero L, Fraga J, Aragüés M, GarcíaDíezA. Massive scrotal. Calcinosis. Dermatol Surg 2002; 28:745.

\section{Conclusion:}

We conclude that scrotal calcinosis is a rare benign disease in the absence of any systemic metabolic disorder occurs as purely idiopathic and due to dystrophic calcification of pre-existing epithelial cysts. 